\title{
MODELO DE ENSINO PARA MUDANÇAS COGNITIVAS: FUNDAMENTAÇÃO E DIRETRIZES DE PESQUISA
}

\author{
Orlando Aguiar Júnior' João Filocrc Saraiva²
}

\section{Resumo}

Apresentamos, justificamos e fundamentamos um modelo de ensino baseado nas três etapas piagetianas de construção de conhecimentos: aytríades dialéticas que Piaget e colaboradores denominam etapas INTRA, INTER e TRANS. Sugerimos que o modelo pode tornar-se um instrumento auxiliar para a pesquisa e para a prática pedagógica no que se refere ao planejamento didático e à construção de currículos. Finalmente, descrevemos ações e pesquisas que estamos desenvolvendo com o intuito de, por um lado, dar validação empírica ao modelo apresentado e, por outro, aprimorar sua utilização enquanto instrumento de formação continuada de professores.

\section{Abstract:}

We present, justify and set the foundations of a learning model based on the three piagetian stages of knowledge construction: the dialectic triads that Piaget and associates called the INTRA, INTER and TRANS stages. We suggest the model may become a helpfui instrument for both research and teaching practice, particularly in terms of planning and curriculurn development. We finish by describing research and actions we are conducting with the purpose of, on the one hand, giving empirical validity to the model and, on the other hand, developing its appiication as an instrument for teacher continuous education. 


\section{INTRODUÇÃO}

O construtivismo tem sido identificado como a mais influente tendência de pesquisa e de inovações educacionais na área de ensino de Ciências (Duit,1993; Fensham, Gunstone \& White, 1994). A imagem de que o conhecimento é ativamente construído pelo aprendiz e não apenas transmitido pelo professor e passivamente apreendido por aque" ${ }^{11}$ é hoje um lugar-comum não apenas entre pesquisadores mas tam iém no discurso de boa parte dos professores de todas as áreas.

Talvez o principal impacto das orientações construtivistas esteja na atenção antes dirigida aos métodos de ensino, entendidos como técnicas capazes de ensinar com eficiência, e a partir de então focalizada nos processos de aprendizagem. O olhar do educador dirige-se, assim, para as potencialidades e as dificuldades dos estudantes em suas interações com os conteúdos escolares.

Segundo Ogborn (1997:131), o construtivismo educacional insistiu corretamente em quatro pontos essenciais, sendo por esses reconhecido: 1. importância do envolvimento ativo do aprendiz; 2. respeito pelo aprendiz e por suas próprias ideias; 3. entendimento da ciência enquanto criação humana; 4. orientação para o ensino no sentido de capitalizar o que os estudantes já sabem e dirigir-se às suas dificuldades em compreender os conceitos científicos em função de sua visão de mundo.

As pesquisas de orientação construtivista, embora tenham provocado um impacto indiscutível nas concepções e práticas em ensino de ciências, demonstram lacunas, equívocos e reducionpsmos que têm sido alvo de críticas recentes (Miliar, 1989; Solomon, 1994; Matthews, 1992; Osborne, 1996). Do nosso ponto de vista, tais fragilidades decorrem de quatro problemas, a saber:

1. imprecisão teórica de parte desses estudos em relação às fontes utilizadas;

2. pretensão ingénua de constituir-se em uma Teoria Geral que pudesse informar toda a pesquisa em ensino de ciências;

3. reducionismo dos problemas educacionais às suas dimensões psicológicas;

4. passagem direta do plano epistemológico para o pedagógico como se a aprendizagem escolar seguisse necessariamente os mesmos passos da construção histórica do conhecimento científico.

Dentre as lacunas que têm sido identificadas nas pesquisas de orientação construtivista, destacamos a questão dos mecanismos que regulam as aprendizagens e o problema do ordenamento das dificuldades relativas aos conteúdos de ciências, questão central para o desenvolvimento de currículos (Osborne, 1996). Além disso, o problema considerado crucial por tais abordagens, ou seja, a aprendizagem escolar concebida como processo de mudanças conceituais, permanece sujeito a várias interpretações e com resultados ambíguos quanto à efetividade das mudanças almejadas.

Fazemos parte de um grupo de pesquisa em ensino que tem procurado extrair da obra de Piaget implicações e desdobramentos de uma concepção construtivista dos processos de aprendizagem ao ensino de ciências, de maneira a fornecer respostas para questões como aquelas enumeradas acima. Para tanto, temos feito o esforço de aliar o rigor teórico em relação às suas formulações origi- nais à necessidade de considerá-las a partir dos problemas específicos do ensino de ciências. Buscamos, ainda, coordenar as contribuições dessa abordagem a outros resultados e perspectivas de pesquisas em educação em ciências, evitando a pretensão de que o construtivismo piagetiano venha a constituir-se em 
uma espécie de metateoria para a pesquisa educacional. É necessário, ainda, dizer que nos ocupamos especialmente dos trabalhos realizados pela Escola de Genebra na década de 70, período no qual Piaget realiza estudos dirigidos aos aspectos funcionais da construção do conhecimento, aspectos esses que nos parecem ter importantes desdobramentos para a educação escolar (Saraiva, 1991).

Em trabalho anterior, analisamos os impactos de conceitos derivados da epistemologia e da psicologia genéticas para o problema da mudança conceituai em sala de aula, no contexto da educação em ciências (Aguiar Júnior, 1995). Apontamos a necessidade de compreender a aprendizagem escolar enquanto processo prolongado no tempo, mediado pela ação e pela intervenção docente, e construído sobre uma dialética entre continuidades e rupturas do pensamento científico em relação ao pensamento de senso comum que permeia as concepções espontâneas dos estudantes em suas estratégias de resolver problemas colocados pela realidade cotidiana.

A partir dessas contribuições iniciais e ainda incipientes, Filocre formulou um modelo didático original destinado a promover mudanças cognitivas. Tal modelo, apresentado em conferência no XII SNEF, serviu de base para o desenvolvimento de projetos de ensino no Curso de Especialização em Ensino de Ciências e, mais recentemente, na preparação dos cursos no bojo do Programa de Educação a Distância do $\mathrm{CECIMIG}^{1}$. O modelo de ensino proposto consiste, basicamente, em uma orientação geral que permita organizar e planejar a intervenção docente de modo compatível com os mecanismos funcionais que regem os processos de aprendizagem.

\section{O Currículo Fundamentado em Bases Construtivistas}

O planejamento de ensino nos coloca, enquanto professores, diante de decisões extremamente complexas e constitui-se, certamente, em uma das mais importantes habilidades profissionais de um educador. Alguns autores (Pacca e Viliani, 1992) enfatizam a centra-lidade desse tipo de atividade enquanto estratégia de desenvolvi- mento de cursos de capacitação de professores. No CECIMIG, passou-se a adotar, com sucesso, um modelo de formação de professores no Curso de Especialização em Ensino de Ciências que tem, como elemento central, o desenvolvimento de Projetos de Ensino e a elaboração de materiais didáticos (Borges, Filocre e Gomes, 1996).

Pode-se considerar o planejamento de ensino a partir de suas várias dimensões, ou seja, a partir das contribuições da sociologia da educação, da psicologia da aprendizagem, da epistemologia, da história da ciência, da estrutura formal do saber a ser ensinado e da didática. Evidentemente, seria um equívoco pensar que um modelo de ^ensino poderia ser capaz de configurar todas essas variáveis. Entretanto, podemos avançar em direção a um modelamento dessa complexa atividade, quando pensamos em compromissos gerais no que se refere aos processos de construção de conhecimentos.

Um modelo de ensino assentado em princípios construtivistas pretende orientar teoricamente a ação docente, no sentido de permitir um entendimento mais abrangente dos processos de aprendizagem que ele pretende promover. Ele deve ser geral o bastante para que possa adequar-se às várias circunstâncias e orientações curriculares, mas suficientemente preciso no sentido de conferir princípios estruturadores para a intervenção didática. Nesse sentido, o modelo se distingue de um método ou de uma técnica de ensino, uma vez que pressupõe flexibilidade quanto aos meios ou às estratégias de ação e reflexão continuada sobre os princípios que a orientam. 
O procedimento tradicionalmente consagrado pela perspectiva condutivista, que ainda orienta boa parte das formas de conceber o processo de ensino e de aprendizagem em ciências, consiste na máxima de "partir do mais simples para gradualmente ascender ao mais complexo". Estamos de acordo com esse princípio de senso comum conquanto se esclareça o que se entende por "simples" e por "complexo". Segundo essas abordagens, o critério de organização dos conteúdos é um critério estabelecido pela lógica da disciplina, ou seja, pelo estatuto de maior ou menor generalidade dos conceitos, de forma a identificar as noções básicas ou elementares de cada domínio do saber. Assim, concebe-se o ensino de química a partir da noção "elementar" do átomo, o ensino da biologia a partir do estudo das células, o ensino da eletricidade a partir da noção básica de cargas pontuais, o ensino da mecânica a partir do movimento na ausência de forças, e assim por diante.

Em termos de lógica disciplinar, partir do mais simples para o mais complexo resulta num paradoxo, na medida em que os conceitos fundamentais da ciência foram forjados a partir de um complexo processo de simplificação e idealização solidários à construção de um corpo teórico consistente. Assim, o movimento inercial (retilíneo e uniforme) é simples apenas para aqueles que se encontram já de posse de uma teoria que assim os concebe. Em ciências, o simples é o real depurado, transformado, simplificado e organizado (Hosoume, Kawamura e Menezes, 1994). Mesmo se assim não fosse, a apresentação gradual e axiomática de conceitos resulta numa atividade enfadonha e sem qualquer significado para os estudantes.

Entretanto, podemos inverter a lógica que concebe o planejamento didático se passamos a considerar o "simples" e o "complexo" não mais a partir das noções no interior de uma teoria já constituída, mas a partir das relações e de seu manejo pela inteligência que busca aproximar-se dessa teoria. Halbwachs (1975:158), a esse respeito, afirma que: "se nos situarmos na perspectiva do funcionamento da inteligência do sujeito, veremos imediatamente, a partir das pesquisas em psicologia, que existe uma hierarquia [de relações] (e uma sucessão temporal na história do desenvolvimento), de tal maneira que algumas dentre elas são manejadas mais precocemente e mais facilmente do que outras. Essa hierarquia de relações que faz referência ao sujeito pensante é totalmente diferente da hierarquia das noções (simples ou compostas) que refere-se ao objeto em si".

Organizar um currículo ou um planejamento didático segundo a lógica da aprendizagem, e não segundo a lógica das noções que compõem a estrutura da disciplina já constituída, implica considerar o conhecimento enquanto processo, enquanto verdade provisória. Estabelecer um modelo construtivista de ensino implica, portanto, estabelecer níveis de conhecimento que se pretendem promover e atividades e mediações que se julgam necessárias para proporcionar o entendimento dos estudantes numa dada direção.

O essencial, nessa abordagem, é a ideia de que conhecemos e estruturamos o real em seus movimentos, em suas provisoriedades. Isso implica uma recursividade no currículo em que as noções não são apenas revisitadas em diferentes contextos e em diferentes momentos do processo educacional, mas apreendidas em diferentes níveis de compreensão (Doll, 1997). O conhecimento não se dá por meros acréscimos de elementos a serem simplesmente compostos entre si, mas em totalidades que são engendradas em suas superações. 


\section{O Modelo de Ensino para a Mudança Cognitiva}

O modelo de ensino que examinamos recorre à epistemologia genética para extrair dela elementos que auxiliem o professor na identificação desses níveis de estruturação e, assim, orientar suas escolhas didáticas. O projeto central da epistemologia genética foi justamente o de identificar leis gerais que permitam compreender o porquê dessa sucessão nas formas de conhecimento e dos mecanismos que as engendram. Numa grande síntese desse projeto, Piaget e Garcia (1987) identificam, na psicogênese e na história das ciências, mecanismos comuns na construção de conhecimentos. O elemento que os autores consideram de maior importância nesse estudo comparativo consiste na tríade dialética constituída pelas etapas INTRA, INTER e TRANS, quando se trata de precisar o sentido das superações e as características de cada nível ou estado de conhecimento em relação àqueles que o precedem e o sucedem.

O primeiro nível, INTRA, refere-se ao estatuto de qualidades e atributos conferidos aos objetos do conhecimento, com relações precárias ou insuficientes entre si. Esse primeiro nível é característico das primeiras abordagens de um novo domínio. Na psicologia genética, o nível INTRA é facilmente identificado com as representações infantis no estágio pré-operatório. Assim, por exemplo, a sombra pertence ao objeto e não tem qualquer relação com a luz que a projeta (quando estamos sob uma árvore e perguntamos à criança o que foi feito de nossa sombra, obtemos a surpreendente resposta de que está escondida na sombra da árvore). Os problemas são resolvidos por justaposição de qualidades através das quais procura-se explicar os fenómenos: um objeto pode bater forte porque é pesado, ou parar pelo mesmo motivo, andar lentamente porque é grande, ou seguir rapidamente porque tem muitas rodas, e assim por diante.

Entretanto, conferir um estatuto INTRA a determinado nível de elaboração de conhecimentos não implica fazer qualquer juízo sobre as competências operatórias do sujeito. Todos nós, adultos escolarizados, temos essa reação cognitiva quando nos deparamos com objetos de conhecimento com os quais temos pouca ou nenhuma experiência. Nesse caso, procuramos estabelecer qualidades observáveis que permitam conferir sentido à experiência. À medida que, procuramos destacar cada uma delas, procedemos a uma leitura parcial da realidade a ser compreendida, pela ausência ou insuficiência de relações e transformações que o modelo, ainda incipiente, permite estabelecer. Devemos, ainda, lembrar que, de todas as reações cognitivas, essa é a mais primitiva e, portanto, aquela que demanda menor esforço e concentração por parte de quem a formula. Desse modo, em várias circunstâncias de nossa vida social (inclusive em algumas situações escolares), procedemos assim, porque a situação não nos parece suficientemente encorajadora, desafiadora ou mesmo interessante.

O mais importante, entretanto, é que esse primeiro nível de elaboração não é apenas primitivo no sentido de frágil e sujeito a modificações, mas ainda no sentido de prover instrumentos básicos de leitura da situação-problema, de configurar um primeiro e necessário nível de compreensão dos fenómenos. Assim, por exemplo, a atividade de acender uma lâmpada de lanterna através de um fio e uma pilha permite ao sujeito destacar certas qualidades daquilo que chamamos circuito elétrico. Mesmo que supondo incorretamente que na lâmpada a eletricidade se transforme em luz, esse primeiro nível promove o entendimento geral de que algo "passa" pelo circuito, além de definir a necessidade de um caminho fechado que vá de um pólo a outro da pilha, passando pelo 
filamento da lâmpada. Dentre os progressos desse nível, podemos destacar a representação da lâmpada, com o filamento e suas conexões.

O segundo nível de entendimento é denominado INTER, no sentido de interobjetal. Ele apoia-se nas construções anteriores, na medida em que, a partir das leituras elementares dos observáveis, o sujeito passe a coordená-los entre si. Os elementos essenciais, nessa fase INTER, são as relações e transformações as quais são engendradas a partir da multiplicação dos esquemas identificados no nível anterior, o que, cedo ou tarde, se converte em fonte de contradições. No esforço de superar essas contradições, o sujeito passa a trabalhar com relações entre variáveis e não apenas com a leitura da realidade a partir de cada uma delas isoladamente. Um bom exemplo desse tipo de procedimento ocorre quando a criança deixa de se ater apenas às qualidades dos objetos para prever sua flutuação ou não na água (grande/pequeno, pesado/leve, fino/grosso, comprido/curto, etc) e passa a estabelecer relações (peso do objeto $X$ peso da água ou ainda peso do objeto $X$ peso de mesmo volume de água). Esse exemplo também nos mostra que, ao estabelecer tais relações, o sujeito vê-se obrigado a rever e reorganizar as propriedades e os atributos que ditavam sua compreensão anterior do sistema. Outra característica dessa fase INTER em relação à precedente consiste na ênfase às transformações em detrimento da atenção antes dirigida aos estados. Enquanto no nível anterior o sujeito atem-se às características que permitem explicar o "modo de ser" dos fenómenos, neste nível, a atenção volta-se para as relações entre os estados inicial e final e para os modos como, partindo de um estado, chegamos ao outro. Devemos lembrar, ainda, que a compreensão de tais transformações envolve a reversibilidade operatória e a atribuição de conservações que permitam ligar mentalmente um estado a outro.

Finalmente, o terceiro elemento da tríade é o nível TRANS, em que o sujeito submete as relações e transformações colaterais do nível precedente a uma estrutura de totalidade que as engloba e justifica. O nível TRANS comporta não apenas uma maior generalidade (aumento por extensão) mas uma compreensão mais articulada, na medida em que o modelo teórico permite prever e demonstrar, além de simplesmente constatar regularidades. As teorias científicas são constituídas não apenas pêlos conceitos com os quais se representa o mundo mas, e sobretudo, pelo modo particular com o qual se concebem as relações desses conceitos entre si e com a estrutura teórica que lhes confere unidade e coerência. Uma vez mais, não se trata de simples acréscimos graduais mas de uma reorganização completa, de uma nova síntese possível graças às realizações que a precederam e às novidades que the conduziram a prosseguir.

É preciso esclarecer, ainda, que a descrição desses níveis INTRA-INTER-TRANS comportam diferentes escalas conforme a abrangência com que se pretenda configurar o domínio de 


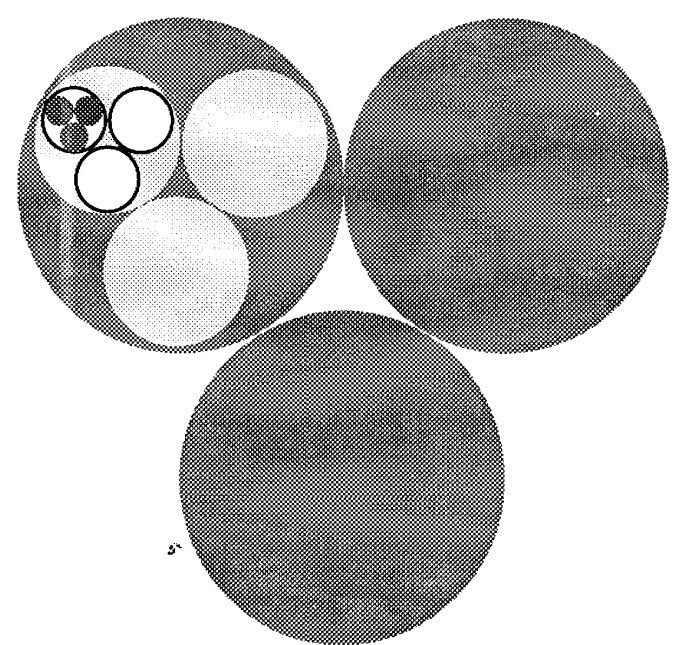

Figura I: representação dos níveis

conhecimento em questão. Além disso, eles extrapolam seus limites, na medida em que o nível TRANS de uma tríade cedo ou tarde, irá configurar-se enquanto mera descrição de propriedades de um sistema (por mais abstraio que sejam as "características" do mesmo). Assim, a mecânica newtoniana, que constitui uma síntese do movimento de afirmação de uma nova cosmologia em oposição ao universo aristotélico-ptolomaico, irá constituir-se em um nível INTRA quando comparada aos desenvolvimentos posteriores, seja na própria mecânica clássica, seja, e sobretudo, na formulação das mecânicas quântica e relativística. O essencial a esse respeito não são as características particulares de um dado estado de conhecimento, mas o processo de estruturação, de superação de formas primeiras de conhecimento por outras progressivamente mais equilibradas.

No modelo de ensino proposto, cada um desses níveis de conhecimento - INTRA, INTER e TRANS - comporta, ele mesmo, a tríade. Isso significa que, em qualquer nível que se considere, teremos presentes:

1. elementos que descrevem os observáveis (INTRA);

2. elementos que permitem ao sujeito configurar um funcionamento ao sistema (INTER) e 3. uma "teoria"² que o torne capaz de explicá-lo (TRANS). Disso resulta um processo de estruturação do real na forma de fractais, que indicam o modo como as formas de entendimento mais primitivas são superadas por outras que aumentam seus poderes de assimilação, ao mesmo tempo em que modificam os instrumentos que utiliza para dar sentido à realidade (nessa representação os níveis mais externos são os mais abrangentes, o que configura um movimento em espiral).

Um exemplo nos ajudará a compreender o modelo proposto. O quadro seguinte refere-se ao planejamento de um curso de eletri-cidade básica ${ }^{3}$, oferecido a professores de ciências, e orientado segundo diretrizes que nos parecem compatíveis com a introdução desse terwa na oitava série do ensino fundamental.

\section{Desenvolvimento do Entendimento de Circuito Elétrico}

As linhas do quadro ao lado descrevem níveis sucessivos de conhecimento com os elementos INTRA, INTER e TRANS destacados em colunas e associados a cada um deles. Tais elementos definem: 
1. as características através das quais o sujeito descreve o objeto ("o que é isso?");

2. suas relações e transformações ("como funciona?");

3. os modelos que utiliza para conferir uma dada interpretação a esses fenómenos ("como se explica?"). Os níveis assim desenhados comportam um planejamento de ensino, ou seja, definem aquilo que se pretende alcançar e desenvolver através de um conjunto de atividades, textos e interações promovidas pelo referido curso. Dessa forma, a cada um dos níveis de ensino fazemos corresponder um bloco de atividades do curso com a intenção de fornecer mediações capazes de aproximar os estudantes das metas estabelecidas.

Os níveis de entendimento assim configurados não constituem uma mera transposição de níveis de desenvolvimento de noções revelados em estudos psicogenéticos, nem tampouco dos níveis históricos de formulação desses modelos por parte de uma comunidade de especialistas. Embora compatíveis com essas formulações históricas e psicogenéticas, o modelo proposto é original na medida em que pretende conferir patamares desejáveis de entendimento do sujeito frente a problemas que lhe são colocados pela ação pedagógica. Por isso, constitui um modelo didático-pedagógi-co que, valendo-se das contribuições da psicologia da aprendizagem e da epistemologia, procura dar-Ihes uma nova significação, decorrente da intencionalidade da educação escolar e da dinâmica própria das interações e mediações por ela promovidas.

Podemos notar, ainda, uma progressiva abstração dos níveis propostos, tanto no que se refere aos observáveis do objeto -características do circuito elétrico - quanto no que se refere às relações e transformações engendradas por esses elementos aos modelos explicativos dos quais o sujeito lança mão para interpretar os fenómenos e prever seus resultados. O planejamento sugere que, num primeiro momento, o aluno começa por definir Os-circuito por seus elementos mais exteriores (fios, pilhas e lâmpadas) e pelo modo como se conectam, definindo uma certa interpretação acerca do mesmo - a lâmpada acende porque a eletricidade passa pêlos fios. Os novos observáveis destacados no segundo nível brilho das lâmpadas, corrente elétrica, distribuição de energia e resistência elétrica -apoiamse e são tornados possíveis graças às contribuições do nível precedente, mas não estão simplesmente nele incluídos. Na representação através de fractais, vemos que os três elementos (INTRA, INTER e TRANS) de um nível convertem-se no primeiro elemento (INTRA) do nível seguinte. Entretanto, esse novo patamar de observáveis contém mais do que os elementos de partida, sendo uma reorganização dos conhecimentos diante dos novos problemas enfrentados pelo sujeito.

1. As "teorias" a que nos referimos incluem as "teorias em ação" (Karmiloff-Smith e Inhelder, 1 975) que orientam a atividade da criança e as "teoria implícitas" (Pozo,1987) que o sujeito utiliza sem que sinta a necessidade de refletir sobre elas, de forma a explicitar seus argumentos ou precisar o sentido de cada uma das noções que utiliza para interpretar o mundo a sua volta.

3. O curso "Aprendendo Eletricidade através de Experiências", de autoria dos Profs. Oto Neri Borges e João Filocre, foi oferecidos a professores da Rede Estadual de Ensino em 1996, em convénio firmado pelo CECIMIG com a SEE-MG. 
A característica central da análise piagetiana é, a nosso ver, essa tensão dialética entre continuidades e rupturas. De um lado, a construção do conhecimento não é um salto no vazio: a única possibilidade de compreensão de algo é a partir do já sabido. De outro, as superações não acarretam simples acréscimos mas restruturações genuínas em que o sujeito é levado a negar aspectos que julgava consolidados, a questionar certas crenças já estabelecidas. Assim, aquilo que o sujeito constrói em um nível se constitui nos observáveis do nível seguinte, em ponto de partida para novas elaborações.

Esses elementos (INTRA, INTER e TRANS) no interior de cada nível de entendimento compõem uma dada visão sobre o objeto do conhecimento e são interdependentes. Assim, os observáveis (INTRA) são orientados por um modelo explicativo (TRANS) por mais elementar que seja este e, ao mesmo tempo, delimitam as transformações e relações que o sujeito é capaz de estabelecer (INTER). Seja de um modo mais elementar, seja através de teorias refinadas e abstraias, todo nível de conhecimento configura uma certa resposta a estas três perguntas fundamentais ao objeto:

1. O que é isso?

2. Como isso funciona?

3. Como se explica?

Podemos dar um estatuto geral INTRA ao primeiro nível de conhecimento, uma vez que demasiadamente centrado em características externas de> circuito elétrico e com noções insuficientemente diferenciadas para que possamos estabelecer relações e transformações mais complexas. O segundo nível, centrado nas relações entre corrente, resistência elétrica e brilho das lâmpadas pode ser designado INTER objetal, À medida que se estabelece uma diferenciação entre energia e corrente elétrica, os princípios de conservação garantem uma análise geral do circuito e suas transformações. Entretanto, as explicações referem-se, ainda, a leis gerais com modelos explicativos incipientes, com uma análise precária do circuito enquanto totalidade auto-regulável. O terceiro nível, TRANS, realiza não apenas um refinamento do nível anterior, mas principalmente configura um modelo microscópico para a corrente e a resistência elétrica.

Segundo Piaget e Garcia (1987:40), a existência e generalidade dessas sucessões INTRA-INTER-TRANS na construção do conhecimento constitui o melhor dos argumentos em favor de uma epis-temologia construtivista. O empirismo poderia explicar a passagem do INTRA ao INTER já que se trata da passagem de predicados a relações e as mesmas podem surgir por simples constatações. Mas a passagem do INTER ao TRANS comporta a construção de composições necessárias e não mais simplesmente gerais, o que só seria possível recorrendo ao papel ativo do sujeito do conhecimento. Quanto ao apriorismo, a dificuldade estaria não mais em explicar a construção dessas totalidades, mas em compreender por que elas devem ser preparadas por análise de qualidades e atributos (INTRA) e por relações e transformações (INTER).

Essa discussão espistemológica tem consequências pedagógicas importantes. Enquanto a pedagogia de orientação condutivista compõe um currículo em que as aprendizagens são organizadas numa sequência linear e acumulativa, boa parte dos modelos de ensino de ciências voltados para a promoção de mudanças conceituais cometeram o erro oposto ao ignorar a existência de patamares intermediários entre os conhecimentos prévios dos estudantes e os grandes princípios estruturadores do pensamento científico. Alguns autores (Hewson, 1981; Posner et alli, 1982; Carey, 1985) 
postulam a existência de tipos distintos de mudança: de um lado, as mudanças "fortes", "radicais" ou de "troca conceituai"; de outro, mudanças "fracas", de "captura conceituai". Entretanto, tais abordagens não estabelecem nenhuma relação entre as várias formas de mudanças e concentram seus esforços na promoção daquelas mais profundas, dirigidas aos elementos centrais e organizadores do pensamento científico, justamente aqueles mais difíceis, porquanto mais afastados das interpretações de senso comum. Nos termos do modelo que apresentamos, é como se pretendêssemos alçar ao nível TRANS, sem ter consolidado os níveis INTRA (centrado nas propriedades e atributos do sistema) e INTER (voltado para o desenvolvimento de relações e transformações).

O modelo proposto pretende estruturar o ensino de maneira a permitir, reconhecer e valorizar os progressos dos estudantes bem como a considerar suas dificuldades na compreensão das formas mais elaboradas de conhecimento, consagradas pelo pensamento científico. Para tanto, ele não está centrado apenas nos estados finais de conhecimento que pretende promover, mas especialmente nos mecanismos de passagem, de estruturação; portanto, na definição de níveis intermediários e dos elementos (INTRA, INTER e TRANS) que compõem cada nível. Pretende-se, assim, tirar o máximo proveito daquilo que o estudante já sabe, ou seja, sublinhar a heurística positiva de suas concepções e ideias prévias. Em lugar de um discurso científico simplificado, o que se propõe é a evolução de ideias, a partir de uma construção teórica simples, fundamentada em certas crenças da criança e orientada para construções cada vez mais abstraías e generalizadas. O modelo consiste, pois, em uma terceira via para o ensino, uma vez que nega tanto a apropriação fragmentada e segmentada dos conhecimentos quanto a possibilidade de compreensão de uma totalidade sem 0 ir e vir dos conceitos e das relações em suas diferenciações. $A$ representação das mudanças na forma de fractais pretende salientar a continuidade funcional desses processos e as rupturas ou descontinuidades estruturais nas formas de entendimento por eles engendradas. Entretanto, parece-nos necessário acrescentar a esse modelo elementos que permitam orientar a ação docente no que se refere à introdução dos alunos nas formas de entendimento próprios do pensamento científico, o que configura, a nosso ver, novas rupturas.

Várias pesquisas (Víllani, 1992; Driver et alli, 1994; Désaulteis e Larrochele, 1990; Guidoni, 1985) têm indicado que os elementos centrais das mudanças ultrapassam a dimensão propriamente conceituai e apontam na direção de rupturas do pensamento científico em relação às normas consagradas pelo senso comum em situações usualmente rotineiras da vida cotidiana (Berguer e Luckman, 1994). Por essa razão, optamos por designar o processo de aprendizagem em ciências como conjunto de vivências que configuram mudanças cognitivas e não apenas mudanças conceituais. Por estrutura cognitiva entendemos um sistema de atribuição de significados; por extensão, a expressão mudança cognitiva pretende destacar mudanças de ponto de vista de um dado sujeito em relação a um dado objeto de conhecimento. A intenção é a de contar com uma descrição mais ampla do processo, de forma a contemplar não apenas os elementos conceituais, como também as atitudes diante de situações potencialmente perturbadoras, a disponibilidade para rever convicções anteriores e submetê-las à argumentação racional, os procedimentos utilizados para validar hipóteses ou conjecturas, os procedimentos utilizados para processar informações, etc. Nesse sentido, um dos desafios a essa pesquisa é o de configurar estratégias e instrumentos que permitam lidar com essas transições nas formas de conhecimento para além dos aspectos conceituais. 


\section{O Modelo de Ensino Enquanto Hipótese de Trabalho}

O fato de ser bem justificado teoricamente não significa que o modelo proposto seja de fato eficaz em realizar aquilo que propõe. Assim sendo, temos realizado um conjunto de investigações e ações no sentido de verificar empiricamente sua validade na organização do currículo, no planejamento pedagógico e na formação docente.

O Curso de Especialização em Ensino de Ciências do CECIMIG/FaE-UFMG oferece, em seu currículo, um conjunto de disciplinas denominadas "Desenvolvimento de Projetos de Ensino", que totalizam seis créditos e cuja finalidade é a de prover meios através dos quais os alunos, ao final de um ano de trabalho e estudos, desenvolvam Projetos de Ensino acerca de conteúdos de ciências segundo determinada fundamentação teórica. Nos últimos anos oferecemos essa disciplina cuja meta foi a de elaborar um planejamento de curso e desenvolver seus materiais de ensino segundo o modelo proposto. A turma de 1997, por exemplo, produziu quatro trabalhos que envolveram os temas: campo magnético, sexualidade e corpo humano, educação ambiental e concepções e práticas no ensino experimental em ciências. A qualidade dos trabalhos apresentados e o envolvimento do grupo oferecem-nos uma indicação favorável quanto às possibilidades do modelo enquanto instrumento para a formação continuada de professores.

Uma outra equipe, a de professores do CECIMIG responsáveis pêlos cursos oferecidos no "Projeto de Capacitação de Professores a Distância: Interlocução Mediada pela Tecnologia" estabeleceu como meta de pesquisa orientar o planejamento de todos os cursos de acordo com o modelo de ensino proposto, procurando, assim, verificar a validade do mesmo enquanto instrumento auxiliar na organização de materiais instrucionais e também na formação de professores.

Duas hipóteses iniciais orientam nossa pesquisa. A primeira delas consiste na suposição de que o contato com o modelo seja instrumento de desenvolvimento profissional dos professores. Tal desenvolvimento se daria em duas direções complementares - de um lado, fornecer instrumentos teóricos e conceituais para situar as propostas de ensino e estabelecer relações destas com os processos de aprendizagem que pretende desencadear; de outro, embora fortemente sustentado por elementos teóricos, constituir-se em convite à ação, em instrumento para a materialização dessas intenções educativas na prática pedagógica. O modelo permite, assim, uma reflexão sobre o papel da escola e do ensino de ciências na prática presente e futura. A nossa suposição é a de que o professor, para interagir com o modelo e desenvolver propostas concretas de ação nele inspiradas, deve necessariamente assumir seus pressupostos. Conversas informais com os professores que passaram por essa vivência parecem confirmar essa hipótese.

A segunda hipótese é a de que as reações de professores com diferentes experiências e vivências profissionais sejam bastante diferenciadas, com exigências e demandas distintas no que se refere à necessidade de aprofundamento teórico e de concretização prática. O grupo de professores do CECIMIG, com rica vivência na produção e no desenvolvimento de cursos e propostas de ensino, mostra-se inicialmente mais refratário àquilo que lhes parece uma camisa de força para o desenvolvimento de suas propostas. Além disso, parece-nos razoável supor que certas características do modelo sejam antecipadas pela prática desses professores e refli-tam-se em suas propostas, o que as torna de certa forma menos necessárias. Já nosso contato com os alunos do Curso de Especialização indica a necessidade de fortes mudanças e a existência de obstáculos a serem ultrapassados, mas também uma maior adesão por parte dos mesmos quando 
sentem que o modelo oferece respostas a problemas enfrentados em sua prática profissional e para os quais não têm soluções à vista.

É preciso, ainda, indicar algumas dificuldades na assimilação desses princípios organizadores da prática educativa. A primeira delas refere-se à compreensão dos aspectos externos do modelo proposto, relativos às descrições dos conteúdos em termos de categorias INTRA, INTER e TRANS, sem que isso se faça acompanhar por compromissos quanto aos princípios norteadores do modelo. Em alguns casos, em lugar de rever, refletir e, eventualmente, modificar seus modos de ação pedagógica, o professor apenas adapta seus modos de conceber e organizar o ensino à linguagem e à forma proposta pelo modelo. Uma segunda dificuldade, que nos parece ainda mais desconcertante, refere-se ao fato de que, ao desenvolver um certo modo de apresentar e organizar os conteúdos do ensino, o professor acaba por concebê-los implicitamente como sendo o caminho para a aprendizagem e não como um dos múltiplos caminhos possíveis. Dessa forma, as relações entre ensino e aprendizagem passam a ser foco de uma atenção especial de nossas reflexões atuais sobre as possibilidades e limites do modelo proposto. Finalmente, um terceiro tipo de obstáculo reside no grau de sofisticação do saber docente que demanda sua operacionalização prática no planejamento de um tópico de conteúdo.

Mudando o foco de atenção da formação de professores para a validação do modelo enquanto instrumento adequado para promoção de aprendizagens significativas, pretendemos acompanhar a im plantação de cursos planejados com essa perspectiva de forma a verificar se as intenções do modelo de ensino, voltado para a oti-mização de oportunidades de mudança cognitiva, efetivam-se na prática. Para a coleta desses dados, pretendemos acompanhar o desenvolvimento de cursos oferecidos pelo Projeto de Educação a Distância, através dos registros indicados pelas interações promovidas via rede de computadores bem como por meio de entrevistas semi-estruturadas com os professorescursistas.

É importante salientar que as possíveis vantagens e problemas do curso a distância em relação aos cursos presenciais serão pano de fundo e não elemento dessa pesquisa. Essa forma de interação via Internet facilrta a coleta de dados - coleta essa que foi feita num dado momento do curso -, mas oculta as formas e condições de produção, ou seja, o que o professor-cursista fez para chegar àquela resposta. Entretanto, esse modo de coleta de dados parece ser adequado aos nossos objetivos - evidenciar a ocorrência ou não de mudanças significativas no entendimento dos conceitos em estudo e de representações acerca da ciência e de seu processo de produção. As entrevistas com alguns participantes do curso pretendem, por sua vez, validar e esclarecer aspectos relacionados aos dados assim coletados.

Finalmente, o modelo de ensino proposto tem-nos servido de instrumento auxiliar nas mudanças atualmente em curso na Rede Estadual de Ensino de MG, decorrentes da implantação do regime de progressão continuada e da organização do trabalho pedagógico em ciclos de formação. Os ciclos de formação têm, por meta, uma melhor adequação entre os tempos escolares e os tempos de aprendizagem, com uma flexibilização do currículo de forma a respeitar os diferentes ritmos e estilos de aprendizagem dos alunos. Para isso, a SEE-MG estabeleceu um programa-piloto de inovações curriculares e de capacitação de professores, a ser desenvolvido ao longo do presente ano e, posteriormente, estendido a todas as escolas da Rede. A fim de que os currículos se tornem instrumentos auxiliares para que os professores possam lidar com essa nova realidade, pretende-se que os mesmos 
sejam recursivos na apresentação e no desenvolvimento de ideias e conceitos considerados centrais em cada área de conhecimento. A recursividade dos currículos coloca, na ordem do dia, os níveis de complexidade na apresentação e no desenvolvimento dos conteúdos e os patamares de entendimento que se pretende desenvolver em cada etapa do processo de formação do educando. O desenvolvimento de um currículo de ciências com tais características e o processo de avaliação da aprendizagem por ele demandado abrem amplas possibilidades de investigação.

\section{A Guisa de Conclusão}

Um modelo de ensino assentado sobre os aspectos funcionais que regem a aprendizagem abrem a possibilidade de superar o confi-namento do construtivismo pedagógico às séries iniciais do ensino fundamental. A nosso ver, foi dada ênfase equivocada aos aspectos estruturais da Teoria Genética de Piaget, deixando-se de lado os elementos funcionais que regulam a formação dos conhecimentos. Tais aspectos não foram, ainda, devidamente explorados pela pesquisa educacional e trazem consequências fundamentais para a análise e a formulação de propostas pedagógicas.

Cabe, também, ressaltar que, aos aspectos funcionais da formação dos conhecimentos - sintetizados pelas três questões básicas mencionadas ("O que é isso?"; "Como funciona?"; "Como se explica?")-, acrescenta-se outro, relativo às dimensões psicológicas e afetivas do sujeito da aprendizagem. Tal dimensão se expressa mediante uma quarta questão: "o que isso tem a ver comigo?". Trata-se, aqui, dos aspectos que ditam os modos de interação do sujeito com os objetos de seu conhecimento, e que lhe dirigem (ou, ao contrário, tornam difusa) a atenção e o esforço na identificação e resolução de contradições, conflitos e lacunas.

Neste trabalho, procuramos fundamentar esse modelo bem como indicar os esforços de pesquisa que têm sido realizados com o objetivo de examinar seu alcance e suas possibilidades. Esperamos, em breve, poder relatar os resultados dessas pesquisas.

\section{REFERÊNCIAS}

AGUIAR, Júnior. O. (1995). Mudança Conceituai em saia de aula: o ensino de ciências numa perspectiva construtivista. Belo Horizonte: Centro Federal de Educação Tecnológica. (Mestrado).

BERGER, P. \& LUCKMANN, T. (1994). A construção social da realidade; Tratado de Sociologia do Conhecimento. Trad. Floriano Fernandes. Petrópolis: Vozes, 11a edição (original publicado em 1966).

BORGES, N. O .; FILOCRE, J. e GOMES, A. E. (1996). Modelos de Desenvolvimento de Materiais Didáticos para o Ensino de Física e Ciências. Encontro de Pesquisa em Ensino de Física, 5, Águas de Lindóia, SP. Atas do V EPEF.

CAREY, S. (1985). Conceptual change in childhood. Cambridge: MIT Press. 
DÉSAUTELS,J. \& LAROCHELLE,M. (1990). A constructivist pedagógica! strategy; the Epistemological Disturbance (experiment and preliminary results). In: HERGET,D.E. (ed.) More History and Phiiosophy of Science in Science Teaching. Florida State Universitty: Tallahassee.

DOLL, Jr. W. (1997). Currículo; uma perspectiva pós-moderna. Porto Alegre: Artes Médicas.

DRIVER, R.;^ISOCKO, H.; LEACH, J.; MORTIMER, E. \& SCOTT, P. (1994). Constructing Scientific Knolwledge in the Classroom. Educa tional Researcher, 23(7): 5-12, october 1994.

DUIT, R. (1993). Research on students conceptions; devel-opments and trends. In: International Seminar on Misconceptions and Educational Strategies in Science and Mathematics, 3, Ithaca, NY: Cornell University. Proceedings of the Third...

FENSHAM, P.; GUNSTONE, R. \& WHITE, R. (1994 ). The Content of Science; A constructivist approach to its teaching and learning. Londres: The Palmer Press.

GUIDONI, P. (1985). On natural thinking. European Journal of Science Education, 7(2): 133140.

HALBWACHS, F. (1975). La física dei profesor entre la física dei físico y la física de! alumno. Trad. Reyes de Vilialonga. Paris: Revue Française de Pédagogie, $n^{0} 33$.

HEWSON, P. W. (1981). A conceptual change approach to learning science. European Journal of Science Education, 3(4):383-396.

HOSOUME, Y. KAWAMURA, M. R. \& MENEZES, L. C. (1994). Objetos e objetivos no aprendizado da Física, São Paulo: Publicações do Instituto de Física da USP.

MATTHEWS, M. (1992). Constructivism and empiricism; an in-complete divorce. Research in Science Education, 22: 299-307.

MILLAR, R. (1989). Constructive criticisms. ínternational Journal o f Science Education, 11(5): 587-590.

OGBORN, J. (1994) A vulgar science curriculum. In: JENNISON, B. e OGBORN, J. (eds.) Wonder and delight. Essays in science education en honour of the life and work of Eric Rogers 1902-1990. Londres.

OSBORNE, J. (1996). Beyond Constructivism. Science Education, v. 80, n.1, pp. 53-82.

PACCA, J. e VILLANI, A (1992). Estratégias de Ensino e Mudança Conceituai na Atualização de Professores. Revista Brasileira de Ensino de Física, v. 14, n.4, pp. 222228. 
PIAGET, J. \& GARCIA, R. (1987). Psicogênese e História das Ciências. Trad. Maria F.M.R. Jesuino. Lisboa, D. Quixote (original publicado em 1983).

PIAGET, J. (1976). Equiiíbração das Estruturas Cognitivas. Trad. Marion M.S. Penna. Rio de Janeiro: Zahar.

POSNER, G.; STRIKE, K.; HEWSON, P. \& HERTZOG, W. (1982). Accomodation of a Scientific conception; toward a Theory of Conceptual Change. Science Education, 66(2): $211-227$.

POZO, J. I. (1987). Aprendizaje de la ciência y pensamiento causal. Madrid: Visor.

SARAIVA, J.A.F (1991). Piaget e o Ensino de Ciências; elementos para uma pedagogia construtivista. Fac. Educação,Universidade de São Paulo.(Doutorado).

SOLOMON, J. (1994). Tjie rise and fali of constructivism. Stu-dies in Science Education, 23: 1-19.

VILLANI, A. (1992). Conceptual change in science and science education. Science Education, 76(2): 223-237.

\section{Correspondência:}

Prof. Orlando Aguiar Jr; Universidade Federal de Minas Gerais, Faculdade de Educação, Cecimig;

Av António Carlos, 6627 - Belo Horizonte, MG - cep 31.270-901. Correio eletrônico: orlando@fae.ufmg.br

Submetido em 03/04/98, aceito para publicação em 21/01/1999. 